\title{
Imapct of Modern Gadgets on School Students
}

\author{
N. Mathankumar, S. Mari, K. Thiyagarajan
}

\begin{abstract}
Data Systems (IS) execution in advanced education is a huge venture. Such ventures are required to bring expanded proficiency and viability, just as better quality administrations to partners. Our writing search didn't discover understudy data the executives frameworks (SIMS) in Ethiopia or comparable low-pay nations. This examination is work in progress. It endeavors to connect the writing hole for usage and achievement components of SIMS in a college setting of low pay nations. The investigation will address the exploration question: what determinant elements add to the achievement or disappointment of IS in advanced education establishments in Ethiopia, with specific reference to SIMS? The examination utilizes DeLone and McLean(1992, 2003) IS Success Model to recognize the components of IS achievement when applied to SIMS. We likewise research two new develops top administration backing and client bolster that were discovered pertinent in the examination setting.
\end{abstract}

Keywords - Student information management system, higher education institutions, IS Success Model, information quality, systemquality, user support, top management support.

\section{INTRODUCTION}

Data framework is characterized as an 'accumulation of subsystems characterized by utilitarian or hierarchical limits (Iivari,1991). It underpins basic leadership and control in associations (Lucas, 1981) by using data innovation to capture,transmit, store, recover, control, or show data utilized in at least one business procedures' (Alter, 1996).Like any advanced business area, Higher Education Institutions (abridged as HEIs) need to accomplish and upgrade quality inits working. In any case, these foundations face difficulties during the time spent achieving the goal of turning out to be better quality HEI. McClea and Yen, (2005) expressed that:"In this part the test starts with the foundation's confirmation division. The confirmations division works as the conveyance point for quality information sources, which ought to in the long run become much greater yields. The division, at that point, should gather critical measures of information about understudies just as keep up the capacity to viably examine and change the information into appropriate data. This builds up another capacity for the confirmation office to perform - data

innovation. Data innovation by and by speaks to a basic achievement factor for various associations. Higher

Revised Manuscript Received on December 16, 2019

N. Mathankumar, Department of Science and Humanities, Bharath Institute of Higher Education and Research, Chennai, India. Email: ma.aswinkumar18@gmail.com

S. Mari, Department of Science and Humanities, Bharath Institute of Higher Education and Research, Chennai , India. Email: maripalani09@gmail.com

K. Thiyagarajan, Department of Science and Humanities, Bharath Institute of Higher Education and Research, Chennai , India. Email: thiyagu768@gmail.com instructive establishments fall into this classification and have looked for the status of first movers in connection to the advancement and usage of data innovation all through theare as of the scholarly community" (McClea and Yen, 2005).

The above focuses imply that data framework has become a significant piece of the organization of advanced education and one of the significant regions where data frameworks assumes a key job is the Admissions Department. SIMS is a product application for instructive foundations to oversee understudy information that incorporates understudy affirmation data, course data, data on scholastic evaluations and other understudy related information[1]-[3]. The strategic policies and forms, and the data that aides basic leadership in huge zones of the institute, associate with and get from these data frameworks (Suwardi,2007). Its execution is perhaps the biggest speculation (Suwardi, 2007) in advanced education establishments. The advantages of data innovation in advanced education confirmations get from the fundamental need to build proficiency, support efficiency, and reduction costs while expanding applications and improving the nature of understudies acknowledged into instructive projects (McClea and Yen, 2005).

Gathering, investigating and changing a developing understudy related information into appropriate data is troublesome without the advancement and execution of ICT-upheld IS. Accordingly, Universities and Colleges are as of now contributing on the improvement and execution of SIMS to meet the necessities. Such venture on data frameworks is normal tobring expanded proficiency and adequacy just as better quality administrations to the clients in the territory. In this manner, the estimation of data frameworks achievement or adequacy is basic to our comprehension of the worth and viability of IS the board activities and IS ventures (DeLone and McLean, 2003). In such manner, there ought to be research to distinguish factors that add to the achievement or disappointment of SIMS in HEIs in Ethiopia and other creating nations.

This examination means to make a commitment in tending to data framework achievement factors for actualizing and using Information System as a rule, and SIMS specifically in Ethiopian college framework from a national point of view, a zone wherein our pursuit of the writing yielded little proof of research exercises. As it is expressed by Anakwe, et al. (1999) numerous concentrates on IS execution achievement have been embraced however not many have focused on Least Developed Countries(LDCs). They additionally included that "there is developing worry that execution and usage of IS are being embraced inside adequate thought of monetary, social and political challenges. Recognizing the determinants for IS accomplishment inside these varying settings is significant in LDCs. 
This exploration venture will subsequently endeavor to cross over any barrier in the writing between the Information System usage and IS achievement factors for its utilization in a college setting of low pay nations, for example, Ethiopia[4]-[6]. The examination will address the exploration question: what determinant elements add to the establishments of Ethiopia with specific reference to SIMS? The examination utilizes DeLone and McLean model to distinguish the components of IS achievement when applied to SIMS with regards to a HEIs. Notwithstanding the sex develops of the first model, i.e., data quality, framework quality, use, client fulfillment, singular effect, authoritative effect; client backing and top administration backing are viewed as important to the investigation zone and included as directing variables. Testing whether data frameworks achievement models like DeLone and MacLean's canbe stretched out to research SIMS's prosperity inside a low pay nation setting is the enthusiasm of the investigation.

The paper is sorted out in four segments. The primary segment builds up the reason for the contextual analysis by presenting St. Mary'sUniversity College and its SIMS. The subsequent area manages the hypothetical structure to be utilized in researching the achievement or disappointment of SIMS. This area will exhibit the DeLone and McLean (1992) data framework achievement model, extra develops to be included the model which are determinant factors for the IS accomplishment in our unique situation, meaning of each build and the speculation set for every one of the builds. The third segment introduces the approach to be followed in contemplating the IS achievement factors. In this segment the strategy to be applied, estimation instruments, and test size just as information gathering strategies will be talked about. In the last segment we present our finishing up comments and demonstrate the normal outcomes and commitments of the examination.

\section{A. Conceptual Model}

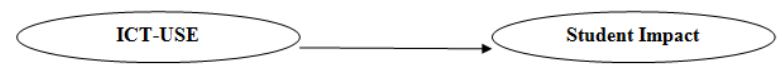

\section{MOTIVATION AND STUDY BACKGROUND}

Investment in the area of SIMS is a high priority in the case of Ethiopian HEIs. This is mainly because of the recent trend of expansion of HEIs and increase in student enrollment. As recently as the year 2005, there were only 9 public HEIs in Ethiopia. In the last three to four years 13 new public universities were built and made operational, raising the number of public HEIs to 22. In addition to this about 250 private higher education institutions have been established in the past ten years, most of which offer diploma and certificate programs. About 55 of the 250 private higher education institutions offer degree programs and 2 of the 250 offer post graduate programs. Therefore, a total of 263 new public and private higher education institutions have been established in the past ten years. This increased the total number of both public and private[7]-[9] achievement or disappointment of IS in advanced education

HEIs to 272. Partly because of this expansion, the average five year growth in tertiary level enrollment reached $27 \%$. This expansion brought significant increase in student enrollment. In order to cope up with such expansions in student enrollment, institutions of higher education are making investment in the development and implementation of IS and it is a most recent phenomenon in the case of Ethiopia. Appropriate evaluation of these systems remains an important agenda for higher education management if they are to see a good return for their costly investment. Thus, our motivation is to conduct this study to help identify determinant factors that contribute to the success or failure of IS implementation and use in HEIs with particular reference to SIMS in Ethiopia using a specific case. We selected St. Mary's University College mainly because of the experiences one of the co-authors as a staff member at the university college during its system development and implementation. Currently the researcher is also a primary user of the system.

St. Mary's University College is a private HEI which was established in the year 2000. It is one of the two private higher education institutions that offer post graduate programs. It also offers degree, diploma and certificate programs in conventional mode (Regular and Extension face-to-face classes) as well as in distance education mode. There are a total of 22 departments in both conventional and distance education mode that offer degree, diploma and certificate programs. The total number of students in both modes is 40,393 , of which 16,833 are degree students, with 20,545 diploma students and3,015 Certificate students in both conventional and distance programs. The total number of full time academic staff is 206,and that of administrative staff is 778.SIMS for the University College is developed in-house based on the requirement specification of the Registrar's Office. The system is developed using PHP programming language with MySQL database. Apache Server is used to configure the system. After properly testing the SIMS it was implemented successfully in September 2008. The system supports functions including storing and processing students' admission data, handling course registration, scheduling classes, entering and processing grades, generating grade reports and transcripts, processing graduation related data and generating statistical reports of different kind for multiple purposes[10]-[12].

SIMS interacts with an independent Exam Correction Software to automatically update its database with new additions and changes of course title, course code, and student data. It also automatically imports grades from the Exam Correction Software. SIMS also interacts with other three packages. One package is software that is used by 16 Coordination Centers of Distance Education at different regions to process and forward results of projects and term papers electronically to the main Registrar Office[13]-[16].

Published By: 
SIMS automatically imports the results from the system. The other package is Exam Attendance Information System which is used by Exam Unit of Distance Education and Departments to incorporate and track student attendance on exam for the courses registered. SIMS also interacts with this system to automatically import exam attendance information. There is also finance software which is known as PayCol. SIMS automatically feeds students' data to Pay Colsystem.

Users of the system include all staff members of Registrar Office, finance office as well as the teaching staff in different departments. The total number of users of the system is about 292. The total number of students supported by the system, as it is stated above, is 40,393. The system has been in use for the past two and half years. At the initial stage of implementation there was data mismatch problem (including student data and course related data) encountered during data migration from the old system to the new one. It took a couple of months to solve this problem. There is no other major problem encountered except the minor ones which were corrected rather painlessly[17]-[19].

\section{THEORETICAL FRAMEWORK}

\section{A. Background on the Model}

Research in the course of recent decades has brought about various ways to deal with the assessment of IS achievement. Some of them include framework utilization, Information Value, client fulfillment and all the more as of late assistance quality. Such changed ways to deal with IS achievement measures recommend absence of understanding in regards to the topic of what establishes IS achievement. One of the normally refered to papers in the writing is that of DeLone and McLean (1992). In their paper, the creators blended 100 observational IS achievement measures (distributed somewhere in the range of 1981 and 1987) and proposed a model that fuses a few individual elements of accomplishment into a general model of IS achievement. DeLone and McLean presented six significant measurements or classes of ISsuccess - framework quality, data quality, use, client fulfillment, singular effect and authoritative impact.According to DeLone and McLean (2003), in the IS Success Model, "frameworks quality" measures specialized success;"information quality" measures semantic achievement; and "use, client fulfillment, singular effects," and "hierarchical effects" measure adequacy achievement. As they have explained, an is first made, containing different highlights, which can be described as showing different degrees of framework and data quality. Next, clients and directors experience these highlights by utilizing the framework and are either fulfilled or disappointed with the framework or its data items. The utilization of the framework and its data items at that point effects or impacts the individual client in the lead of their work, and these individual effects by and large outcome in hierarchical effects. As indicated by Gable et al. (2003), the builds/proportions of the Delone and McLean model gave an all encompassing perspective over the association-from a top the board viewpoint, to that of information passage officials' - and gave a nitty gritty arrangement of progress measurements[20].

As it is expressed in the presentation DeLone and McLean Information System Success Model is utilized as a hypothetical structure for the examination. This is for the most part in light of the fact that the DeLone and McLean structure is broadly acknowledged as one of the more complete IS assessment systems and has been utilized widely in experimental research (Ballantine et al., 1996). The model additionally enablesus to assess the accomplishment of IS at various levels framework, individual and authoritative.

\section{B. Construct Definition and Hypothesis}

Framework quality is a proportion of the data preparing framework itself. Most measures in this classification tap designing focused execution qualities. It comprises of execution attributes of the frameworks which incorporate asset use, unwavering quality, reaction time, simplicity of terminal use, information exactness, dependability, culmination, framework adaptability and usability. On account of Student Information Management System, convenience, reaction time, correspondence with other framework, adaptability and simplicity of learning are the significant characteristics that are esteemed by clients of the Student Information Management System. Seddon and Kiew (1994) found in their way investigation that data quality and framework quality are noteworthy determinants of by and large client fulfillment[21]. The Technology Acceptance Model (Davis et al., 1989) predicts that apparent simplicity of utilization, as a part of framework quality (DeLone and McLean, 1992) is a huge immediate and circuitous determinant of utilization, the roundabout impact being directed through apparent value. It is normal along these lines, that the higher the framework quality, the better the accomplishment of Student Information Management System (SIMS) regarding improved use and client fulfillment. This is spoken to by the accompanying theory. H1a: SIMS quality will be decidedly identified with the utilization of SIMS.

H1b: SIMS quality will be decidedly identified with SIMS client fulfillment.

Data quality speaks to proportions of data frameworks yield. It is a component of the estimation of the yield delivered by a framework as saw by the client. Run of the mill measures here incorporate exactness, accuracy, money, yield practicality, unwavering quality, culmination, succinctness, arrangement and pertinence (Bailey and Pearson, 1983). Different creators additionally included understandability, report helpfulness, adequacy, opportunity from predisposition, equivalence, and quantitativeness. In this examination, data quality is considered as having attributes of exactness, yield practicality, fulfillment, yield clearness and arrangement. 
The framework ought to have the option to give definite data about the understudy including, confirmation status, scholarly status, all out courses taken and staying, all out terms visited and remaining, and grade lacks. Clients ought to affirm that the data gave is exact, auspicious gave, dependable, complete, and showed in proper arrangement. Apositive conformance of these attributes by the clients infers that there is adequacy in the utilization of SIMS. Seddon and Kiew (1994) likewise expressed that data quality is a critical determinant of in general client fulfillment. This prompts the accompanying speculation[22].

H2a: SIMS data quality will be decidedly identified with SIMS use.

H2b: SIMS data quality will be decidedly identified with SIMS client fulfillment.

Top the executives backing is conceptualized as the inclusion and investment of the official or top level the executives of the association in IT/IS exercises (Jarvenpaa and Ives, 1991, refered to in Hussien, et al., 2007). As it is expressed previously, there are various investigations that approved the positive connection between top administration support and IS achievement. Lord and Teo, (1996) discovered top administration bolster encouraged the fruitful sending of vital IS applications, while absence of topmanagement bolster was found to repress its key utilization/IS. Igbaria et al., (1997) tried a basic condition model on individualized computing factors in little firms and discovered administration bolster has positive direct impacts on seen convenience and saw usability. Ang et al., (2001) inspected 47 Malaysian open part organizations on IT utilization to help absolute quality the board (TQM). In this examination top administration support for IT applications is seen as the most elevated indicator of IT use. Every one of these discoveries demonstrated that top the board backing has huge impact on IS achievement. Every one of these discoveries empower us to create theory 3 which is expressed as follows.H3: The impact of framework quality and data quality on SIMS use and client fulfillment is the positive capacity of top the executives support[24].

Client backing is principally worried about the specialized help and help given to clients as far as working the data frameworks in the association (Hussein, et al., 2005). As it is expressed above there are numerous investigations led in the zone which affirmed solid connection between client backing and achievement in client registering. In a mechanized situation where there is ICT based Student Information Management System we accept that specialized help to clients of the frameworks is urgent.

Clients will in all likelihood look for help in utilizing the frameworks in their every day activities. In light of the confirmations, it is conceivable to estimate the connection between client support and IS accomplishment as pursues:

H4: The impact of framework quality and data quality on SIMS use and client fulfillment is the positive capacity of client support. Use alludes to the beneficiary utilization of the yield of a data framework. A portion of the qualities used to quantify data use by various creators include: measure of utilization/length of utilization, number of request, number of capacities utilized, number of records got to, recurrence of access, number of reports produced, consistency of utilization, use for proposed reason, motivation behind use and inspiration to utilize. In our setting "Use" measures everything including information section, information control (edit,delete), grade report and transcript age, factual report age, recovering and any understudy related data and giving it to an outsider. For this situation, use isn't intentional. Along these lines, for this investigation use for planned reason, degree of utilization and number of framework's capacities utilized are viewed as the most suitable. Discord hypothesis by Fishbein and Ajzen (1975, refered to in DeLone and McLean, 1992), recommends that IS use prompts client fulfillment. The discoveries of met an examination led by Bokhari (2005) lead to the decision that there exists a "medium"and critical positive connection between framework utilization and client fulfillment (i.e., $r=$ 0.2555). Notwithstanding these, SIMS use is an immediate predecessor of individual effect factors. In this way, considering these connections the accompanying theory can be made for SIMS use.

H5a: SIMS utilize has positive association with and prompts client fulfillment $\mathrm{H}$ 6: SIMS use will be emphatically identified with individual effects of the SIMS. Client fulfillment can be characterized as the degree of which clients accept the data framework accessible to them meets their data and framework prerequisites (Baroudi et al., 1983). Client fulfillment is a regularly utilized proportion of framework achievement.

A portion of the attributes which are considered as determinants of client fulfillment include: generally fulfillment, data fulfillment - contrast between data required and got, happiness, programming fulfillment, and basic leadership fulfillment. In our specific circumstance, client fulfillment is a significant methods for estimating the degree of fulfillment of framework clients, i.e., representatives of the college school while utilizing the framework during the time spent information section, information control, report age, data recovery and arrangement to the necessary body (counting the administration, Ministry of Education, Education Bureaus, understudies, various divisions, coordination focuses). Some of client fulfillment attributes which are applicable to the investigation are by and large fulfillment level, degree of reliance on the framework, expanded status of representatives, individual advantages picked up, affirmation of handiness of the framework.

Baroudi et al., (1986) recommend that if client fulfillment is translated as a frame of mind, the Theory of Reasoned Action (Fishbeinand Ajzen, 1975, refered to in DeLone and McLean, 1992) bolsters the model that client fulfillment will impact goals to utilize the framework and genuine use. It is normal that the level of client fulfillment can influence the measure of utilization of SIMS. Also, since client fulfillment is an immediate forerunner of individual effect factors the previous influences the last mentioned. In this manner, in view of these connections we build up the accompanying theories in connection to client fulfillment develop.

H5b: SIMS client fulfillment will be decidedly identified with the utilization of SIMS. 
H6: SIMS client fulfillment will be decidedly identified with individual effects of the SIMS.

The individual effect measurement is characterized by DeLone and McLean (1992) as "the impact of data on the conduct of the beneficiary". A portion of the attributes which are considered as determinants of individual effect include: data getting, learning, precise understanding, data mindfulness, data review, issue distinguishing proof, choice viability, improved singular profitability, and assignment execution. Those qualities which are most applicable to the examination are execution related issues. As per Bokhari (2005), "The prime reason for bringing IS into an association is to improve singular basic leadership execution as well as by and large authoritative productivity and viability. The normal gains as far as authoritative objectives through IS usage and selection are worried about the achievement of the framework". Consequently, the effect on singular execution ought to in the long run have some authoritative effect. In this way, the potential theories that can be manufactured is the accompanying:

H7: The effect on singular execution will be identified with the authoritative effects of SIMS

\section{RESULTS AND DISCUSSIONS}

A survey instrument will be used to gather data to test the relationships shown in the research model. Primary users of the system at the university college will be surveyed with a view to soliciting their views and assessment of the system being used. The target population includes all staff members of the Registrar Office and Finance Office, the teaching staff and the top management of the university college. The total number of respondents is expected to be292[25]. Three complementary methods will be used for collecting primary data: questionnaire, interview and direct observation of Student Information Management System and services. The questions are drawn from previously validated instruments and adapted to the current study context. Information on the instruments or measures ispresented in Appendix A. The study will use perceptual measures to capture data on IS success factors. Perceptual measures are acceptable measures in most survey research. A five-point Likert scale will be used to represent the responses of the subjects.

\section{CONCLUSION}

The discoveries of this work in progress study will show the significance of IS achievement factors in deciding the adequacy of SIMS applications in the advanced education condition. This paper will make four significant commitments. To begin with, it offers understanding of estimating the accomplishment of IS with regards to advanced education foundations of low pay nations, for example, Ethiopia. Second, it shows which variables can become predominant in the achievement of a framework, particularly when it is created in-house. Third, the recognizable proof of progress components will help the top the board to concentrate on these variables and make the fundamental mediations. Fourth, it will open an opportunity and exercises learned for further inquire about in the territory. All in all, this will be both a hypothetical and commonsense commitment to the field of IS achievement when actualized in HEIs; specifically HEI in low salary nations may profit by the exercises learned. Since this is to a greater extent a model structure study, separated of our future arrangement is to lead exact research to approve the builds displayed in the model.

\section{REFERENCES}

1. Vasanthi, S. \& Rabiyathul Basariya, S. 2019, "Influence of value analysis and cross training in industry", International Journal of Engineering and Advanced Technology, vol. 8, no. 6, pp. 1810-1811.

2. Velvizhi, R., Sri Gowtham, S. \& Jeya Priya, D. 2019, "Examination of early feedbacks for effective product retailing on E-commerce websites", International Journal of Engineering and Advanced Technology, vol. 8, no. 6 Special Issue 2, pp. 703-706.

3. Anuradha, C., Pothumani, S. \& Kavitha, R. 2019, "A novel method towards E-commerce", International Journal of Engineering and Advanced Technology, vol. 8, no. 6 Special Issue 2, pp. 535-538.

4. Thomas, J. \& Rabiyathul Basariya, S. 2019, "A study on the issues of financial ratio analysis", Indian Journal of Public Health Research and Development, vol. 10, no. 3, pp. 1079-1081.

5. Ramachandran, S. \& Rabiyathul Basariya, S. 2019, "Online marketing study on customer satisfaction and relationship", Indian Journal of Public Health Research and Development, vol. 10, no. 3, pp. 1072-1078.

6. Priya, R., Vinothini, G. \& Cor Jesu, C.D. 2019, "The mentor-protégé relationship for professional growth", Journal of Advanced Research in Dynamical and Control Systems, vol. 11, no. 9 Special Issue, pp. 1110-1119.

7. Jannifer Rani, N., Bina Pani, S. \& Nimisha, N.S. 2019, "A study on money back polices available in LIC", Journal of Advanced Research in Dynamical and Control Systems, vol. 11, no. 9 Special Issue, pp. 833-839

8. Saillaja, V., Jhansi Rani, K. \& Catherine, R. 2019, "Global marketing management planning and organization", Journal of Advanced Research in Dynamical and Control Systems, vol. 11, no. 9 Special Issue, pp. 489-493.

9. Saillaja, V., Jhansi Rani, K. \& Catherine, R. 2019, "The new phase of marketing information system", Journal of Advanced Research in Dynamical and Control Systems, vol. 11, no. 9 Special Issue, pp. 482-488.

10. Thoufiqulla \& Raju, D.V. 2019, "Perception of indian investor towards investment in mutual funds with special reference to mip funds", Journal of Advanced Research in Dynamical and Control Systems, vol. 11, no. 5, pp. 177-183.

11. Jasmine, K.R.M. \& Basariya, S.R. 2018, "A study on the customers benefits on mutual funds", International Journal of Civil Engineering and Technology, vol. 9, no. 4, pp. 45-48.

12. Vasanthi, S. \& Basariya, S.R. 2019, "Pros and cons of on the job training versus off the job training", International Journal of Scientific and Technology Research, vol. 8, no. 10, pp. 671-674.

13. Pavithra, J. \& Ganesan, M. 2016, "A study on awareness and impact of micro-financial schemes", International Journal of Applied Business and Economic Research, vol. 14, no. 8, pp. 5449-5460.

14. Pavithra, J., Dilli Babu, P. \& Ambuli, T.V. 2014, "A study on budgetary control at Maruti Service Masters, Chennai", International Journal of Applied Business and Economic Research, vol. 12, no. 2, pp. 151-161.

15. Gunaraja, T.M. \& Venkatrama Raju, D. 2018, "Determining factors of organisational climate with reference to leadership styles", International Journal of Mechanical Engineering and Technology, vol. 9, no. 9, pp. 1327-1332.

16. Gunaraja, T.M. \& Venkatrama Raju, D. 2018, "The role of job satisfaction and training of employees in determining organisational climate of a selected industry", International Journal of Civil Engineering and Technology, vol. 9, no. 8, pp. 1266-1269.

17. Aarathy, T.S. \& Raju, D.V. 2018, "Performance appraisal and its effects on employees with respect to it sector in Chennai city", International Journal of Civil Engineering and Technology, vol. 9, no. 6, pp. 1535-1538. 
18. Aarathy, T.S. \& Raju, D.V. 2018, "Employee perception towards performance appraisal system in IT sector", International Journal of Mechanical Engineering and Technology, vol. 9, no. 5, pp. 131-135.

19. Porselvi, W., Jublee, D. \& Sivanesan, G. 2018, "A study on factors influencing adoption of technology and innovation in banking industry, tamilnadu, India", International Journal of Mechanical Engineering and Technology, vol. 9, no. 5, pp. 789-800.

20. Akessa, G.M. and Dhufera, A.G., 2015. Factors That Influences Students Academic Performance: A Case of Rift Valley University, Jimma, Ethiopia. Journal of Education and Practice, 6(22), pp.55-63.

21. Miller, G. and Shih, C.C., 1999. A faculty assessment of the academic rigor of on-and off-campus courses in agriculture. Journal of Agricultural Education, 40, pp.57-65.

22. Tsinidou, M., Gerogiannis, V. and Fitsilis, P., 2010. Evaluation of the factors that determine quality in higher education: an empirical study. Quality Assurance in education, 18(3), pp.227-244.

23. Farooq, M.S., Chaudhry, A.H., Shafiq, M. and Berhanu, G., 2011. Factors affecting students' quality of academic performance: a case of secondary school level. Journal of quality and technology management, 7(2), pp.1-14.

24. Fitsilis, P., Gerogiannis, V. and Anthopoulos, L., 2014. Ontologies for software project management: a review. Journal of Software Engineering and Applications, 7(13), p.1096.

25. Adams, J.D. and Jaffe, A.B., 1996. Bounding the effects of R\&D: an investigation using matched establishment-firm data(No. w5544). National bureau of economic research.

\section{AUTHORS PROFILE}

N. Mathankumar Assistant Professor, Department of Science and Humanities, Bharath Institute of Higher Education and Research, Chennai, India.

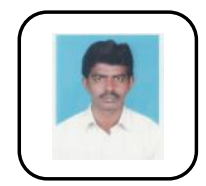

S. Mari Assistant Professor, Department of Science and Humanities, Bharath Institute of Higher Education and Research, Chennai, India.

K. Thiyagarajan Assistant Professor, Department of Science and Humanities, Bharath Institute of Higher Education and Research, Chennai , India. 